\section{ORAL HEALTH RESOURCE LAUNCHED IN EDINBURGH}

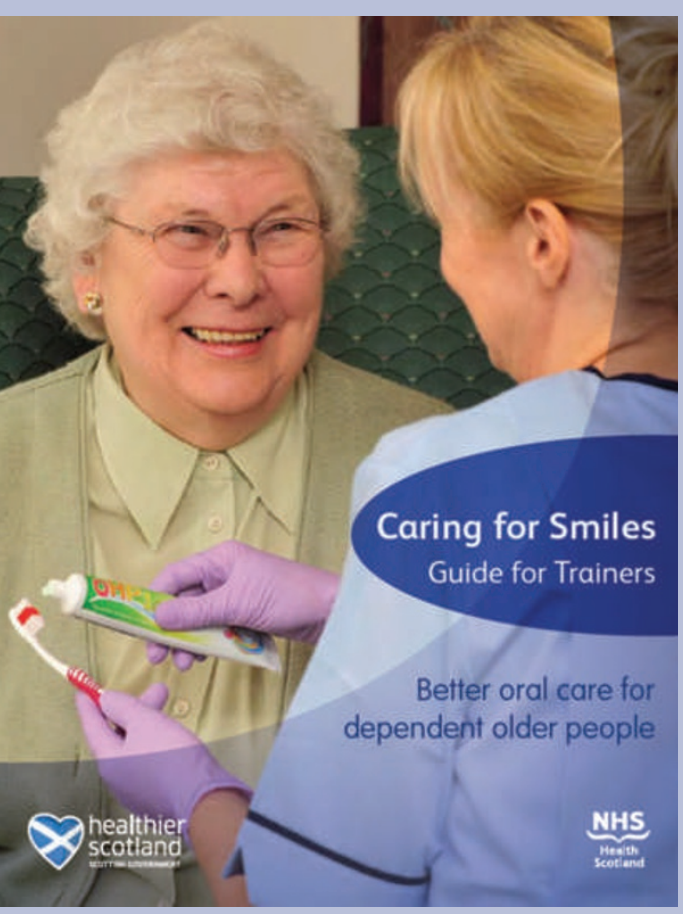

NHS Health Scotland, in partnership with the National Older People's Oral Health Improvement Group, recently launched the resource Caring for smiles at Dynamic Earth in Edinburgh. Thirteen of the 14 NHS Boards in Scotland were represented at the event.

The guide is for oral health professionals to deliver training for staff in care homes and enables carers to provide a high standard of oral care for dependent older people. The training highlights to care staff that good oral health is important for overall general health. It also encourages them to consider that oral care should be an integral part of personal care.

'Good daily oral care will prevent dental disease, pain and suffering and improve the quality of life for dependent older people in care homes in Scotland, said Margie Taylor, Scotland's Chief Dental Officer. 'I encourage all care homes in Scotland to embrace this opportunity, as we seek to help a generation some of whom are no longer able to help themselves.'

Caring for smiles - guide for trainers can be viewed or downloaded from www.healthscotland.com/documents /4169.aspx.

\section{CONFERENCE TO ADDRESS SECONDARY CARE}

'Where are we and where are we going?' will be one of the questions posed at the BDA Hospitals Group annual presidential and scientific meeting. The conference, which will take place on 26 November at Wyboston Lakes, Bedfordshire, will also look at the plans for secondary care in the NHS.

Presentations will be given by Sue Gregory, Deputy Chief Dental Officer, Professor Jimmy Steele and Tony Ireland, Chair of the Consultant Orthodontists Group of the British Orthodontic Society.

The afternoon will focus on temporomandibular joint disorders and on treatment in particular. Dr Justin Durham, Dr Friedy Luther and Dr Vinod Joshi will explore new options that may be simpler, less invasive and have longer-lasting results than the latest designer splint.

A presidential dinner will take place the evening before and the conference will carry 53/4 hours of verifiable CPD. For more information see www.bda.org/groups.

\title{
FIRST CERTIFICATES IN IMPLANT-BASED THERAPY
}

The European Association for Osseointegration (EA0) will award Certificates in Implant-based Therapy for the first time at the annual EAO Congress. This year the event will be held at the Scottish Exhibition and Conference Centre (SECC) in Glasgow on 6-9 October.

As the only Europe-wide standardised assessment of implant-based therapy, the certificate will provide a benchmark for assessing knowledge and skills. The first candidates to participate in the scheme will undergo their final examinations in Glasgow just prior to the awards ceremony.

Candidates will be expected to demonstrate to both patients and regulatory authorities that they are competent to perform straightforward implant treatments. The EAO will only be able to certify a limited number of candidates each year but this is expected to increase as more resources are made available.

More information about the EAO Congress in Glasgow can be found at www.eao.org.

\section{FELLOWSHIP FOR PROFESSOR CHALLACOMBE}

Professor Stephen Challacombe has been awarded Fellowship of King's College London in recognition of his service to the College and its constituent Schools and for his contributions to dental research.

In a career spanning more than 40 years, Professor Challacombe has most recently served as Dean of External Affairs of the King's Health Schools, Chairman of the King's Science Academic Promotions Panel and Vice Dean of the Dental Institute.

Professor Challacombe has been Head of Department of Oral Medicine At Pathology (now Clinical \&t Diagnostics Sciences Group) for 20 years. As an author he has contributed to over 200 papers and 160 other publications, edited seven books and supervised 20 $\mathrm{PhD}$ and MD theses.
'I am very pleased that my work and that of my colleagues who have made my time so enjoyable has been recognised by the College and consider this award a great honour,' said Professor Challacombe.

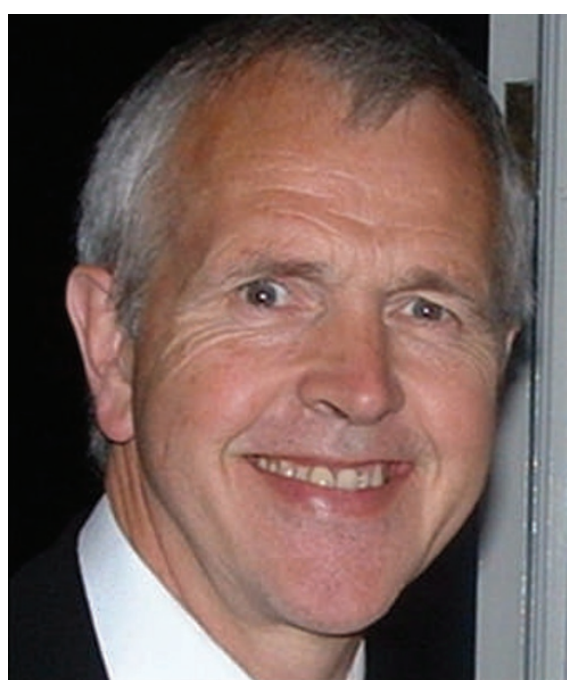

